\title{
Fabrication of Nanofiber Filtration Membranes Using Polyethylene Terephthalate (PET): A Review
}

\author{
Hamidreza Kamrani ${ }^{1 *}$ and Ataollah Nosrati ${ }^{2}$ \\ ${ }^{1}$ Department of Chemistry, Nanotechnology Laboratory, University of Isfahan, Isfahan, Iran \\ ${ }^{2}$ School of Engineering, Edith Cowan University, 270 Joondalup Drive, Joondalup, WA 6027, Australia
}

\begin{abstract}
Application of Polyethylene Terephthalate (PET) in membrane technology for fabrication of nanofiber filtration membranes for water treatment has gained increasing attention in recent years. Some new studies focusing on the application of recycled PET nanofibers in membrane structure have also been reported. Currently, many different chemical and physical methods are being used for water purification. However, membrane technology is becoming more popular and desirable in both domestic and industrial applications. This mini review paper aims to summarize (i) recent developments in synthesis of nanofiltration membranes using PET nanofibers, (ii) some of their different applications for water treatments, and also (iii) survey a new method in membrane fabrication technology for the first time using electrospining technique coupled by Vortex Fluidic Device (VFD) as a new platform for the better membrane fabrication process.
\end{abstract}

Keywords: Membrane fabrication; Membrane; Nanofiber; Electrospining technique

Abbreviations: PET: Polyethylene Terephthalate; VFD: Vortex Fluidic Device

\section{Introduction}

Conservation of water resources is one of the most important current environmental issues which has brought a controversial debate in public discussions in recent years and gained attention of international organizations such as conservation nature and natural resources reservation [1]. Water purification and recycle are also other important challenging problems around the world as without clean water resources the human life will be in danger. To address these challenges, different water purification methods including membrane filtration have been used extensively in recent decades [2,3]. Some other costly and complex technologies have also been developed for purification of salty or saline and drain water resources [4-6]. However, the most rational solution at the moment is conservation of existing sweet water resources [7]. Taking into account that only $0.5 \%$ of the total accessible world water is fresh water, desalination of sea water is a costly purification technique that is performed in places that sweet superficial water is not accessible [8].Water purification is also being considered even in places where the preserving sweet water resources can be achieved by some simple methods such as construction of different types of dams [9]. To date, there have been many studies and efforts for development of new methods for purification of dirty harmful water, containing contaminants or microorganisms, into clean safe water [1014]. These methods usually use nanomaterials such as nanoparticles, nanofibers, nano thin films, Zeolites, carbon nanotubes, etc. [15]. Today, other different water treatment and purification methods for the cleaning of water have been developed with the most common ones being i) Chemical methods such as coagulation, flocculation, flotation, chlorination, filtration, chemical precipitation and ion exchange [1622], ii) Biological treatments and Biodegradation methods such as microbial biomass adsorption [23], microbial degradation [24] and biodesalination [25], and iii) Adsorption techniques involving solid sorbents such as Carbon Nanotubes (CNTs), activated carbon and carbon fiber [26-29]. Amongst all above mentioned classic techniques, adsorption with solid adsorbents is a simpler and cheaper method for water pre-treatment and cleaning. However, one important environmental concern for this method is the necessity for the adsorbent to be environment-friendly, nontoxic and easily removable from reaction media after the consumption. Thus, their toxicity performance and heterogeneity must be considered strictly before their application in industry [16,30]. For example, in water desalination using some nano-composites such as $\mathrm{TiO}_{2}-\mathrm{Cu}$ thin films, the consumed thin film can be removed easily from aqueous matrix without any water pollution after its usage [31].On the other hand, between all well-developed not classic techniques, Membrane filtration is a high-tech effective method for water treatment [11]. In membrane-based water filtration, the membrane is usually a highly porous polymeric thin film or a blend of nanofibers that has the ability of removing very small water pollutants. Different types of membrane filtration include Microfiltration (MF), Ultrafiltration (UF), Nanofiltration (NF), Reverse Osmosis (RO) and Membrane Distillation (MD) [32]. The difference between UF and MF with RO is that UF and MF are commonly used for drainage water treatment that has been used before and need to be refined, while RO is widely used for unused water desalination and also purification. MD is a newer developing technique for desalination of saline water [33,34]. A brief information about different water purification techniques is shown in Table 1 indicating that membrane technology is preferable technique for water purification compared with other techniques [31] (Table 1).

Hence, only this method is discussed in the remaining parts of this paper. Some striking properties of polymeric water filtration membranes have provoked researchers to investigate different polymers in this field. The properties such as hydrophilicity, flexibility in

*Corresponding author: Hamidreza Kamrani, Department of Chemistry, Nanotechnology Laboratory, University of Isfahan, Isfahan, Iran, E-mail: Hr.kamrani@gmail.com

Received May 28, 2018; Accepted June 20, 2018; Published June 30, 2018

Citation: Kamrani H, Nosrati A (2018) Fabrication of Nanofiber Filtration Membranes Using Polyethylene Terephthalate (PET): A Review. J Membr Sci Technol 8: 183. doi:10.4172/2155-9589.1000183

Copyright: ( 2018 Kamrani $\mathrm{H}$, et al. This is an open-access article distributed under the terms of the Creative Commons Attribution License, which permits unrestricted use, distribution, and reproduction in any medium, provided the original author and source are credited. 


\begin{tabular}{|c|c|c|}
\hline Applications & Examples of nanomaterials & Some of novel properties \\
\hline Adsorption & CNTs/nanoscale metal oxides and Nanofibers & $\begin{array}{l}\text { High specific surface area and assessable. } \\
\text { Adsorption sites, selective and more. } \\
\text { Adsorption sites, short intra-particle diffusion distance, tunable surface chemistry, easy reuse. }\end{array}$ \\
\hline Disinfection & Nanosilver/titanium dioxide $\left(\mathrm{Ag} / \mathrm{TiO}_{2}\right)$ and CNTs & Strong antimicrobial activity, low toxicity and cost, high chemical stability, ease of use. \\
\hline Photocatalysis & Nano-TiO2 and Fullerene derivatives & Photocatalytic activity in solar spectrum, low human toxicity, high stability and selectivity, low cost. \\
\hline Membranes & Nano-Ag/TiO ${ }_{2} /$ Zeolites/Magnetite/fibers and CNTs & $\begin{array}{l}\text { Strong antimicrobial activity, hydrophilicity, low toxicity to humans, high mechanical and chemical } \\
\text { stability, high permeability and selectivity, photocatalytic activity. }\end{array}$ \\
\hline
\end{tabular}

Table 1: Comparative information about common water treatment techniques [31].

fabrication, low cost, high thermal resistance, wide $\mathrm{pH}$ tolerances, high mechanical characteristics and other aspects make them good target for membrane technology [34]. As a specific case, PET membrane along with its different fabrication methods and various applications especially in modified form for water treatment will be considered as main issues. Some great properties such as non-toxicity, strength, lightweight, safety, flexibility make PET to a very important and useful raw material that is recognized $100 \%$ recyclable globally. Figure 1 shows the structure of PET polymer which is the most common clear plastic that is used anywhere as domestic consumptions like soda bottle containers (Figure 1).

But PET film compared with bottle form can be a good target for other industrial applications such as membrane filtration technology. The structure of PET having polar groups like oxygen seems to develop a high selective membrane in coupling with specific chemical or biochemical reagent for contaminant removal [35].

\section{Different previous methods for PET membrane synthesis}

Membrane filtration in different forms like polymeric nanoporous thin film or nanofibers with various capabilities are being used in different scales. It is extended from domestic to industrial scales especially for water or wastewater treatment such as industrial wastewater revitalization. It is applied also for water recycle, water softening and cleaning, and separation of compounds having different molecular weights such as different organic or inorganic pollutants. Concerning to the structure of nanofibers or nanopores, the design of nanofiltration membranes with maximum permeability, selectivity and resistance to fouling with optimum pore structure and fibers diameter is very important [34]. Supposed to the third initial aims of this paper, VFD application for PET membrane fabrication in solution form coupled solution electrospining technique will be considered. The output of VFD will be more homogenous PET solution that will be charged into electric field and the result will be more uniform nanofibers. Thus nanofiber membrane filtration will be the basis of discussion for membrane fabrication. The other advantage of nanofiber compared with nanopores is included in high ratio of surface area to its volume that makes it preferable. In this section various methods for PET membrane fabrication are reviewed. The idea of PET membrane usage in water treatment has heightened the investigation of narrow and more innovative studies in membrane technology. The key properties of PET such as stability in acids and organic solvents as well as mechanical resistance have made it the most commonly used material for polymeric membrane fabrication using techniques such as track etching and electrospining [35]. One advantage for application of PET in membrane fabrication rather than other polymers can be the utilization of recycled bottle grade PET as a waste material instead of virgin samples. This is due to the fact that there are no significant differences between virgin and recycled PET samples in terms of physical or chemical properties [36]. Hence, it would be very valuable to vast this technology to both recycled and pure PET instead of just virgin samples. By application of recycled bottle grade PET, not only an environmental pollution problem

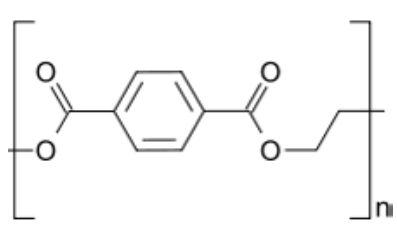

Figure 1: The chemical structure of PET [35]

can be solved, but also fabrication of nanofibers for membrane usage will be achieved at lower cost.. Before application of recycled PET for nanofiber fabrication, it is necessary to consider its physical properties compared with pure or virgin PET samples. In one study by Lee [36], the similarity of recycled PET and virgin PET and their chemical and physical properties was investigated. The result showed no difference in physical properties between recycled PET and virgin samples. It was also determined that chemical and tensile properties of recycled PET are similar to virgin PET [36]. Brennan [37] also studied the properties of fresh and recycled Polystyrene (PS) where there was negligible difference between their mechanical and thermal properties [37]. The same result was also observed for fresh and recycled Polycarbonate (PC) in other studies $[38,39]$. These and other similar studies suggest that there will not be physical restrictions for the usage of recycled polymers like PET for nanofiber membrane fabrication if their extrinsic contaminants are completely removed. A recent study on recycled PET (rPET) by Zander proved the possibility of rPET for nanofiber fabrication. They proved that the mechanical properties of the recycled PET fibers using microtensile tests show the elastic module range from 15 to $60 \mathrm{MPa}$, and in equivalent molecular weight their hardness are comparable or greater than fibers made from commercial polymers [40]. In the following section two main fabrication techniques that are more common for PET membrane fabrication will be explained (i) Electrospining and (ii) Tracked-Etching techniques.

\section{Electrospinning method}

Electrospining method is the first mostly useable and comparatively newer method that is applied for porous membranes including nanofiber filtration membranes [41-43]. This method is divided to two categorizes based on polymeric state during injection to the electric potential; (i) Melt electrospining and (ii) Solution electrospining method. In melt electrospining, first polymer melts and then a charged liquid jet is formed in presence of electrostatic potential to produce nanofiber threads. Electric force is sufficient to overcome the surface tension of droplets. In solution electrospining, first polymer is dissolved in an appropriate solvent and then a charged liquid jet is formed and finally nanofibers are produced that is shown in Figure 2 [34]

According to Tylor [44], fabrication of nanofiber charged threads from drawing viscose melt or liquid droplet is related to maximum instability of the liquid surface induced by the electrical forces. So the 
control of electrical force is very important. In a study by Zander et al. solution electrospining method was used to fabricate nanofiber from recycled bottle grade PET for water filtration to remove microbial contaminants. The estimated diameter of produced PET nanofibers was $\sim 500 \mathrm{~nm}$ and could just filter the particles larger than $500 \mathrm{~nm}$. Filtration and antimicrobial tests showed a good result where $>99 \%$ of the beads as small as $500 \mathrm{~nm}$ were removed using gravity filtration of water (Table 2).

This was a study which for the first time used recycled bottle grade PET (rPET) for water filtration as membrane filtration and the results were remarkable. Hence, for better efficiency the fibers were functionalized with biocidal materials to reduce biofouling [45]. Before this study, the initial idea of recycled bottle grade PET application for making nanofibers by Melt-electrospinning method was developed by Rajabinejad. In this study, first consumed PET bottles were crushed and cleaned and then melt electrospining method was used for nanofiber fabrication. The SEM images showed that the diameter of nanofiber was approximately between $61-93 \mathrm{~nm}$ [46]. In another study solution electrospining process was used to synthesize nano/microfibers of PET, Polystyrene (PS) and Polycarbonate (PC) from the relevant waste plastics and the effect of the used needle diameter and different voltages was considered.The results showed that the average pore diameter size depended on used voltages [47]. A recent review paper has summarized some previous information about Electrospun membranes and some recent developments of membrane technology and their potential impact in two major areas, i.e., desalination and water/wastewater treatment. It involved a summary of previous works on different electospun polymeric membranes and a glimpse about PET membrane as an example [48]. According to mentioned studies, it can vast all studies for the usage of recycled PET the same as pure PET samples because both precursors have same behaviour against fiber fabrication with electrospining method. In the following part, the focus of subject is about virgin PET membrane fabrication.

\section{Track-Etching method}

The other common and simpler technique for nanoporous not nanofiber PET fabrication that can be used for water membrane is track-etching technique that is shown in Figure 3. The Track-etching process is based on the irradiation of a material with swift heavy ions and subsequent chemical etching that makes pores on polymer texture [34]. Wang used the track-etched technique to fabricate PET polymer membranes as one part of a pumping media with low-voltage and high flow rate property. These kind of pumps that are known as low-voltage

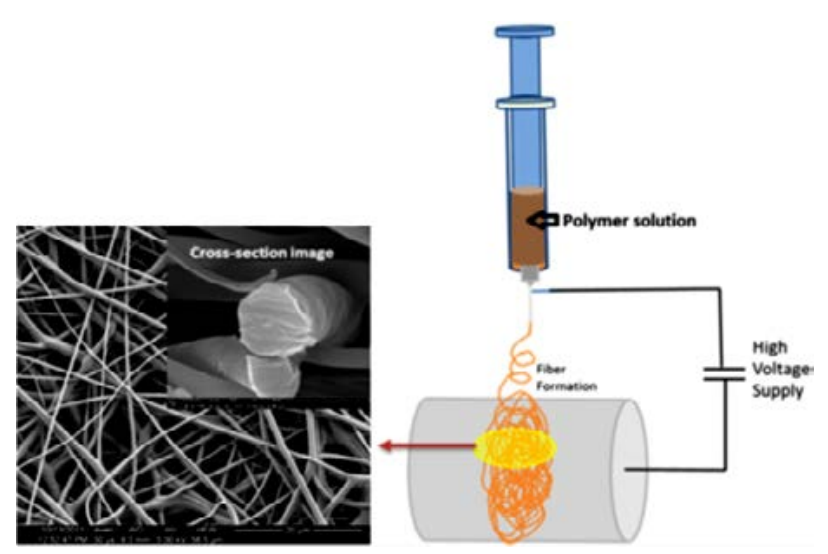

Figure 2: Schematic diagram of electrospining of polymer solution [34].

\begin{tabular}{|c|c|c|c|c|c|}
\hline \multicolumn{7}{|c|}{ Percent captured } \\
\hline $\begin{array}{l}\text { Wt.\% } \\
\text { rPET }\end{array}$ & $\begin{array}{c}\mathbf{2} \\
\boldsymbol{\mu B e a d s}\end{array}$ & $\begin{array}{c}\mathbf{1} \\
\boldsymbol{\mu B e a d s}\end{array}$ & $\begin{array}{c}\mathbf{0 . 5} \\
\boldsymbol{\mu B e a d s}\end{array}$ & $\begin{array}{c}\mathbf{0 . 1} \\
\boldsymbol{\mu B e a d s}\end{array}$ & $\begin{array}{c}\mathbf{0 . 2} \\
\boldsymbol{\mu B e a d s}\end{array}$ \\
\hline \multirow{2}{*}{5} & $99.7 \pm$ & $99.7 \pm$ & $99.3 \pm$ & $21.1 \pm$ & $1.64 \pm$ \\
& 0.07 & 0.01 & 0.9 & 6.2 & 0.7 \\
\hline \multirow{2}{*}{7.5} & $99.4 \pm$ & $99.3 \pm$ & $70.6 \pm$ & - & - \\
\hline \multirow{2}{*}{10} & 0.3 & 0.1 & 4.3 & - & - \\
& $89.9 \pm$ & $49.3 \pm$ & $27.8 \pm$ & - & - \\
\hline
\end{tabular}

Table 2: Filtration efficiency of recycled PET nanofibers determined by fluorescence Spectroscopy about different bead sizes [45].

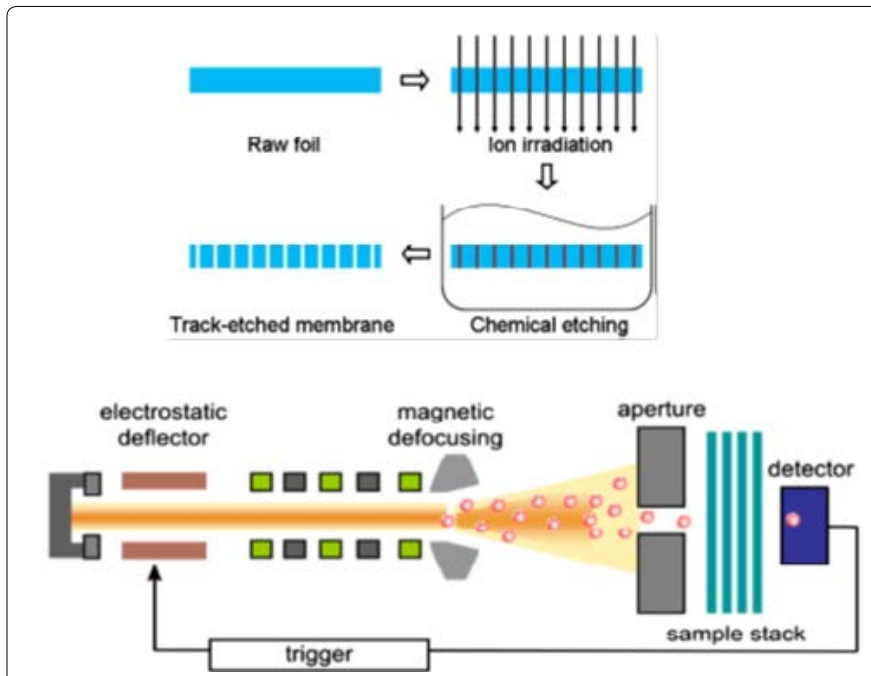

Figure 3: A Scheme of single ion-irradiation used to fabricate track etched membrane [34]

electro-osmotic EO pumps have been suggested to be used in many applications including High Performance Liquid Chromatography (HPLC), micro flow injection analysis, water management in fuel cells, microelectronic equipment cooling, drug delivery, etc. The pore diameter of PET film was in the range of 100 to $250 \mathrm{~nm}$ by regulation of the etching time. EO pump is assembled by two chambers separated by the PET track etched polymer membrane shown in Figure 4 [49].

In another study by Komaki porous PET films were prepared by thermal neutron fission of Uranium-235 radiation and the effect of etching rate on the pore diameter and density on membrane surface was studied. The effective pore diameters were between 10-100 nm and pore densities approximately $108 \mathrm{~cm}^{-2}$ [50]. Another study was reported by Kravets for fabrication of a modified PET membrane in polymeric layer shape obtained by deposition of acetylene on the surface of PET membrane. The process was started by irradiation of PET film by accelerated Krypton ion at a cyclotron. Then ion-irradiated film again was irradiated by ultraviolet light in maximum wavelength at $310 \mathrm{~nm}$. The final procedure was followed by chemical etching resulting in nanofibers' pore diameter of meanly $26 \mathrm{~nm}$. It was concluded that some parameters can influence membrane characteristic that are summarized in Table 3 [51].

Zhang [52] reported a method for fabrication of Nanochannels in different polymer membranes by track-etching technique. In one part of this study both sides of PET thin film first were irradiated with UV light $60 \mathrm{~min}$ in $365 \mathrm{~nm}$ wavelength and then the etching process with single-ions and related chemicals performed to produce nanofiber (nanochannel) with $350 \mathrm{~nm}$ diameter. As a comparative information, 
different shape of PET nanochannels with different etching conditions were produced as shown in Figure 5 and the result are summarized Table 4.

The SEM images showed 350nm diameter of produced nanofibers [52]. Sartowska [53] also reported that by the controlled usage of surfactant on the surface of PET film the formation of asymmetric nanopores in PET film will be possible. This result was achieved first by photo oxidation with accelerated heavy Xe-ions irradiation in one side and the next extra UV irradiation on the other side of PET film. This caused the side with UV light exposure became less susceptible for surfactant adhesion because of photo oxidation. In continue diffusion

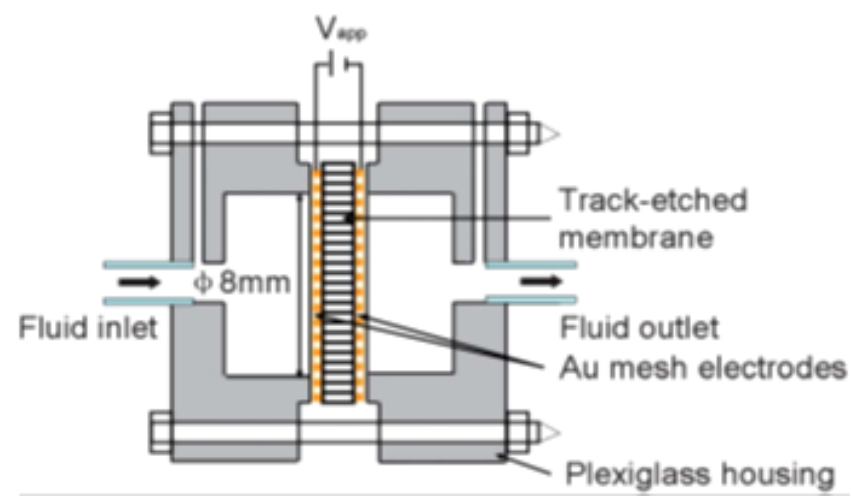

Figure 4: Schematic of the EO pump fabricated from track-etched membrane. The pump has a $130 \mathrm{~mm}$ thick and $0.5 \mathrm{~cm}^{2}$ active cross-sectional area [49].

\begin{tabular}{|l|c|c|c|}
\hline \multirow{2}{*}{ Parameter } & \multirow{2}{*}{$\begin{array}{c}\text { Initial } \\
\text { membrane }\end{array}$} & \multicolumn{2}{|c|}{$\begin{array}{c}\text { Plasma treatment } \\
\text { time (s) }\end{array}$} \\
\cline { 3 - 4 } & & 300 & 600 \\
\hline Relative increase in the mass $(\%)$ & - & 3.7 & 8.2 \\
\hline Thickness of deposited layer $(\mathrm{nm})$ & - & 70 & 150 \\
\hline Air flow rate at $\Delta \mathrm{P}=3 \times 10^{4} \mathrm{~Pa}\left(\mathrm{ml} / \mathrm{min} \mathrm{cm}^{2}\right)$ & 165.0 & 95.0 & 10 \\
\hline Effective pore diameter $(\mathrm{nm})$ & 65.0 & 54.5 & 26 \\
\hline Water contact angle $($ degree $)$ & 65 & 67 & 65 \\
\hline
\end{tabular}

Table 3: Change in the membrane characteristics during treatment by acetylene plasma [51]. of alkali on this side became higher that formed asymmetric PET nanopores. So these two factors; Chemical attack of alkali solution and surfactant effect can control asymmetric nanopores formation in PET film that is shown in Figure 6.

As it was summarized in this section, two main methods for PET membrane fabrication were electrospining and track-etching methods that have better and more effective results. Although previous studies prove that electrospining and track-etching are the best methods for membrane fabrication from rPET or virgin PET, Zander [54] tried to use a different rPET membrane fabrication method. They assessed the possibility of nanofiber fabrication from rPET bottle grade using a Centrifugal Spinning Technique (CST) which is completely different from electrospining method. In CST, polymeric fibers are made by heat source with centrifugal power rather than high voltage in electrospining method. The fabricated fibers have micro size not nanosize diameter without conductivity and solubility in any chemicals. This study involved three different polymers, polypropylene, polystyrene and PET. The results confirmed that all recycled polymer nanofibers show significant capabilities in filtration, textile industry and insulation. SEM images proved that fabricated nanofibers with CST have smooth surface with diameters between 1070-9410 $\mathrm{nm}$ that is enough for water pre-treatment and contaminant filtration. Overall, this study shows that PET nanofiber membrane can be applied at least for water pre-treatment easily, however, further work and using chemicals or biochemical additives is required to make it applicable for specific water purification purpose. For instance, according to Trofimov [55] track-etch modified PET membrane in presence of $\mathrm{N}$-isopropylacrylamide (NIPAM) solution as grafting agent and argon plasma matrix was produced in 30$40^{\circ} \mathrm{C}$ and the efficiency of water filtration was about 2.5 times more than original track membrane. The scheme of PET modification is shown in Figure 7.

\section{Modified PET nanofiber filtration membranes for specific water treatment applications}

PET membrane modification with some chemical or biochemical groups converts it to a more selective tool that can be used for specific applications [56-61]. This part includes a brief assessment of the effect of PET surface modification on PET membrane quality. Recently there have been some novel studies on desalination of water using surface modified PET membranes. For instance Fang [62] could modify PET

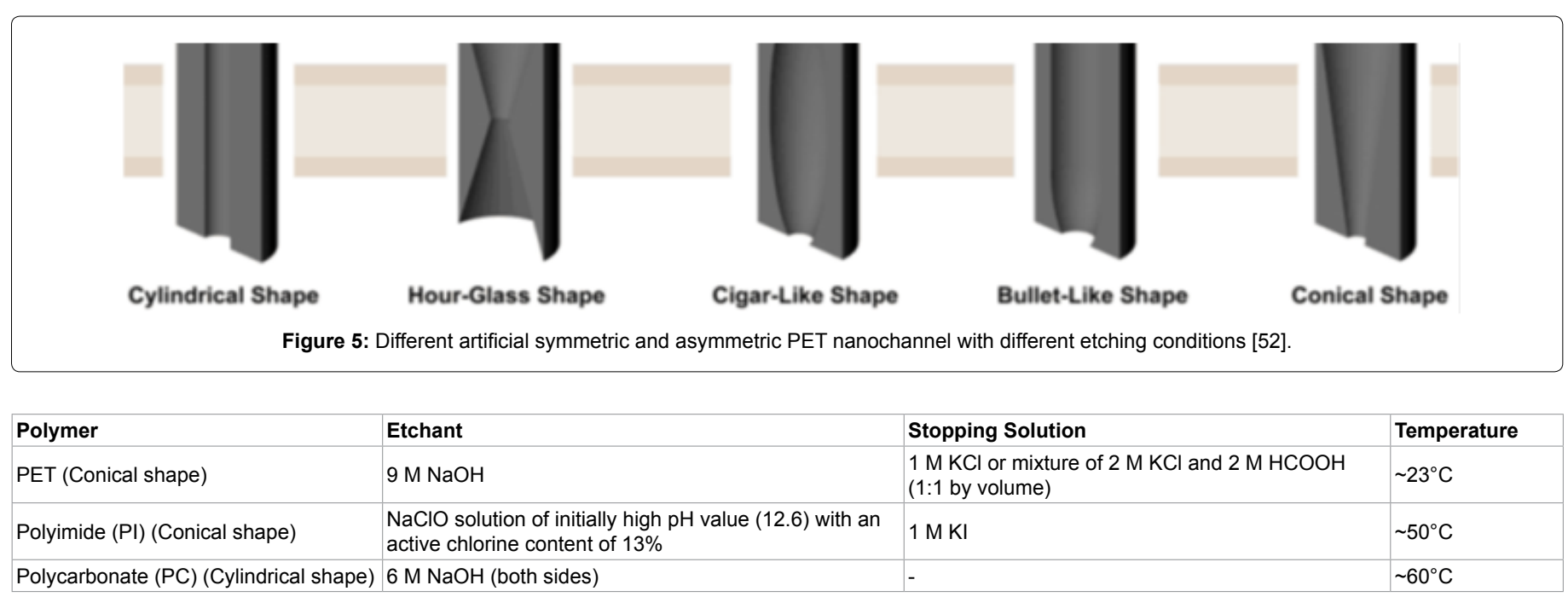

Table 4: The Conditions of different etching processes for different nanochannel membranes [52]. 


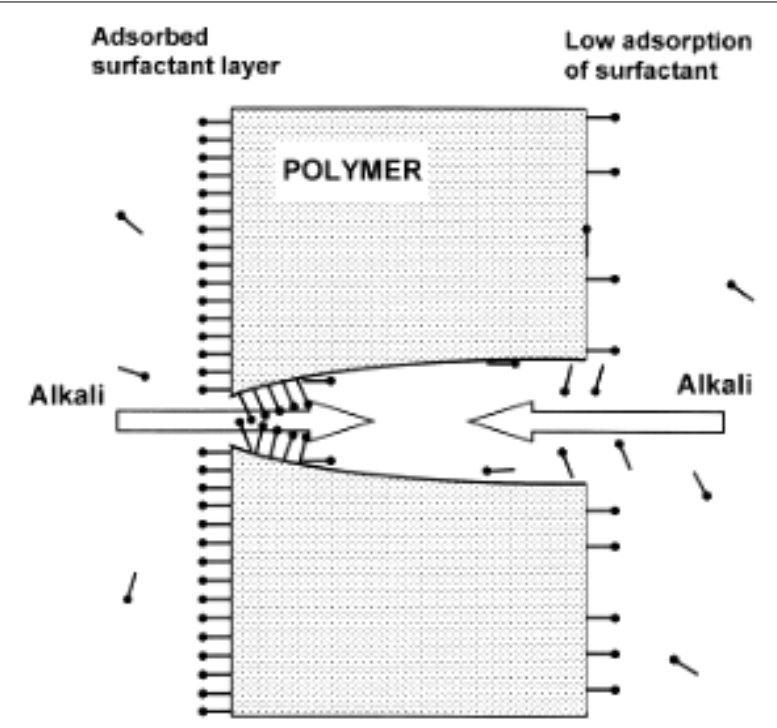

Figure 6: Scheme of track etching in an ion-irradiated polymer film in the presence of nano-sized surfactant molecules [53].

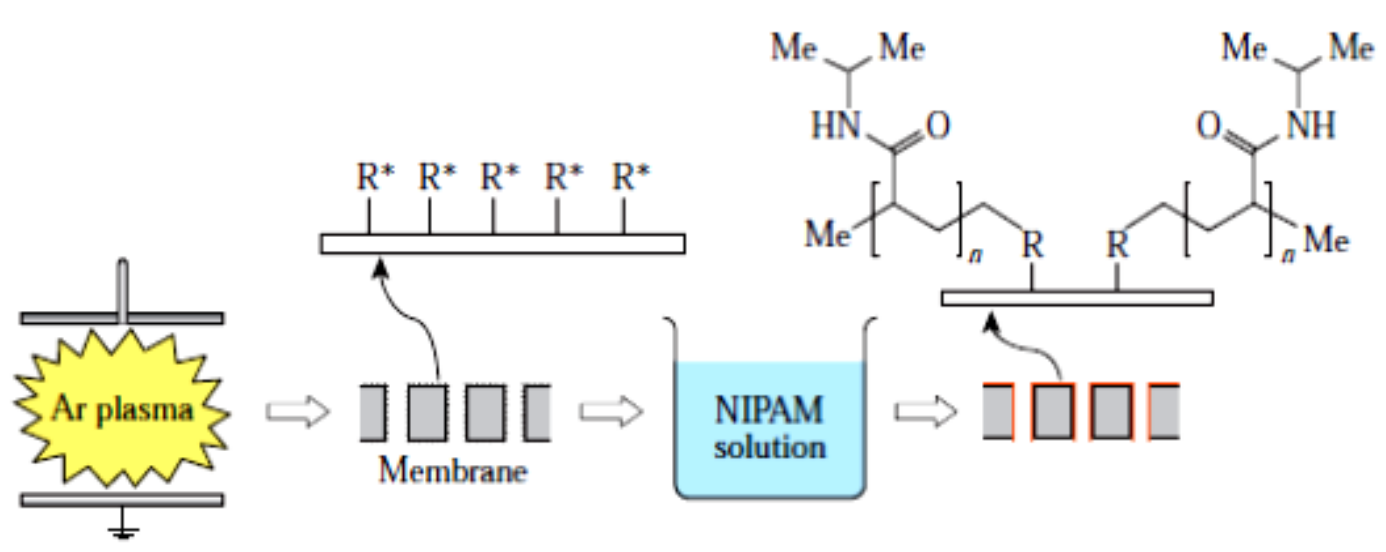

Figure 7: Schematic diagram of PET membrane modification by track-etching process in Arpalasma matrix and NIPAM solution [55]

electrospun nanofibers with natural proteins, such as gelatin and collagen to produce gelatin-grafted PET nanofibers. This study showed apparent enhancement in the spreading and proliferation of vascular endothelial cells on modified PET nanofibers' surface compared with the non-grafted ones. In another study, the effect of polyvinyl pyrrolidone (PVP) on the characteristic of modified membranes made from recycled PET bottles for humic acid removal was investigated. Porous polymeric membranes were prepared via thermally induced phase separation by dissolving recycled PET bottles in phenol. For modified PET membrane, a 5\% wt of PVP was added into PET solution and the final solution was dried slowly at room temperature to solidify the membrane. The tests of humic acid removal from water showed about $75 \%$ rejection by PET-PVP modified membrane compared with pure PET with 25\% humic acid rejection [63]. In a recent study, Kim [64] tried to mimic the desalination characteristics of mangrove roots as a natural membrane for fabrication of PET membrane. By inspiration of natural mangrove roots activity, a modified PET membrane in presence of polyelectrolytes using a layer-by-layer deposition technique was constructed that showed a high sodium ions desalination rate of 96.5 compared with $62 \%$ non-modified PET membrane. Abdel-Hady [65] introduced a commercial PET membrane for fuel cell application based on proton exchange (PEM) that is much better than Naf ion membrane that was applied in previous fuel cells. It was for better application of methanol as fuel cell energy generator instead of fossil fuel cell. PET membrane was a good representative in fuel cells as proton transferring agent in electrolyte, as well as a barrier to the passage of electrons between the electrodes. It can be used in automobile, residential homes, and in portable devices such as laptops and cell phones. Direct Methanol Fuel Cells (DMFCs) are also environmentally friendly compared with fossil cells. For preparation of PET-PEM, PET film was grafted by Styrene in presence of UV radiation and at the end sulfonation of grafted copolymer was performed. The effect of Styrene monomer concentration and irradiation time was tested and optimum percent of Sulfonation and ion exchange capacity was evaluated. Some factors like water uptake, proton conductivity, methanol permeability, sulfonation, ion exchange capacity and tensile strength were tested. Due to better proton conductivity and ion exchange with PET grafted membrane, it can be used in methanol fuel cell with lower cost, higher conductivity, suitable water uptake and low methanol permeability. Uyar [66] used cyclodextrin to modify PET nanofibers surface to improve its ability for 
phenanthrene removal from aqueous solution. The basic method for PET nanofiber production was solution electrospinning that was performed by dissolution of $22.5 \%(\mathrm{w} / \mathrm{v})$ PET polymer in Tetrafloro acetic acid Dichloromethane $(50 / 50, \mathrm{v} / \mathrm{v})$ mixture and the next injection solution into an appropriate potential field. For modification process, the surface of the electrospun PET nanofibers was modified through the grafting reaction between PET and Cyclodextrin (CD). This step was done first by mixture of cyclodextrin solution with citric acid as crosslinking agent and sodium hypophosphite hydrate as catalyst. Then electrospun PET nanofibrous mats were dipped into the resulting solution and kept for $3 \mathrm{~h}$ at $50^{\circ} \mathrm{C}$. The last product after washing was an effective modified PET nanofibers with a higher ability for phenanthrene removal from water compared with pure PET nanofibers. Figure 8 shows the steps of PET nanofiber modification with cyclodextrine.

In another study, Polyethersulfone (PES) nanofibers $(260 \pm 110$ $\mathrm{nm}$ in diameter) were deposited on non-woven PET fibers [67]. The results showed that PES-PET membrane had more mechanical strength because of PET addition and was used for pre-filtration in removal of particles such as E. coli bacteria from water. However, a heat treatment was performed to improve its interfacial stability [67]. Ma [68] fabricated a modified Polyacrylonitrile (PAN)/PET membrane and used two ionic liquids namely, 1-butyl-3-methylimidazolium chloride and 1-ethyl-3-methylimidazolium acetate as solvents to help coating of poorly soluble cellulose on the surface of PAN/PET membrane under mild conditions. The membrane was tested for separation of oil and water mixture and proved higher flux potential with same rejection compared with commercial Ultrafiltration (UF) membrane. In another similar study, Guoliang Li [69] synthesized a PET enhanced cellulose acetate membrane by phase inversion method, where the effect of some parameters such as concentration and temperature of casting polymer solution, temperature and time of evaporation, coagulation and annealing process on membrane performance was evaluated. The produced membrane was tested for salt rejection with appropriate $\mathrm{NaCl}$ concentration as a feed solution and glucose as a draw solution showing a good water flux $\mathrm{L} /\left(\mathrm{m}^{2} \bullet \mathrm{hr}\right)$ and high salt rejection in Forward Osmosis (FO) mode [37]. In another innovative study not for water treatment, electrospun PET non-woven filter mat was applied to apple juice clarification. The final result of produced membrane was a random fibrous arrangement free of beads and high tri-dimensional porous structure with small pore diameters (the average fiber diameter was 420 $\mathrm{nm})$. This new process showed a high flux performance and appeared to be much faster, simpler and more economical than the traditional clarification methods [70]. Jianguo [71] also modified the surface of PET thin film by nano $\mathrm{TiO}_{2}$ particles with low gamma ray plasma to produce a new metalized and polarized PET membrane film with higher resistance to deformation and degradation and higher surface hydrophilicity than commercial PET film [71]. By consideration of all previous laboratory works it becomes clear that these works are very precious but are in small scale and is very important to develop to industrial scales too.

\section{A new synthetic PET nanofiber membrane idea using VFD}

VFD is a novel microfluidic processing platform developed by Colin L. Raston [72]. It involves a rapidly rotating tube that is open in one end and can produce dynamic thin films at high rotational speed for finite sub-millilitre volumes of liquid set with different rotating angle. The shear in the result thin film depends on the speed and orientation of the tube. It works in two modes, continuous flow mode and confined mode. In continuous flow mode, at least two jet feeds inject one or more liquid reactants directly to the closed end of tube under different rotational angles and speeds and provides additional tunable shear and at the same time with the accomplishment of the reaction, the product exits from the tube. Continuous flow devices can facilitate conversion of small scale production to industrial production. It also minimizes waste and energy usage, and in high quantity production can be essentially safer [73]. In confined mode unlike continuous mode, there is not a continuous exiting of products at the top of the tube. Instead, a finite volume of one or more liquid reactants is filled into the tube and under a moderate rotational speed, a vortex of products maintain at the bottom of the tube and after accomplishment of reaction, the product is extracted. This is very similar to simple centrifuge but the only difference is that it can be performed under different angle and extended shearing time and therefore the reaction and its efficiency can be controlled with the balance of gravity and centrifugal force [74]. In the Figure 9 it is shown both VFD working modes.

The Figure 10 shows a scheme of continuous flow mode of VFD and the relationship between the speed of tube rotation and film thickness in a specific rotation angle. As the Figure 10 shows, with increasing in speed in continuous flow mode, the thickness of thin film in a specific angle rotation will decrease.

The main striking VFD advantage opposed to batch processing, where reactions are carried out in a pool of mixture of reactants such as ordinary centrifuge, is dynamic thin films formation that enables intense micro-mixing of the reactants producing effective surface waves within the thin film. The important result will be efficient heat and following mass transfer [75]. Raston [76] have done concentrated researches in application of VFD in different works. In an interesting research VFD was used for controlling reactivity and also selectivity of Diels-Alder reaction as an example. The application of VFD for accelerating organic dimerization reaction of cyclopentadienes, and following aldol and Michael addition reactions, in presence of unusual 2,4,6-triarylpyridines was investigated. Residence times were controlled for continuous flow processing with the viscous flow rates $0.1 \mathrm{~mL} / \mathrm{min}$ in a $10 \mathrm{~mm}$ diameter tube rotating at $2000 \mathrm{rpm}$. The results are shown in Figure 11.

The results were very interesting and the role of VFD was clear [76]. In another following research by Raston [77] using optimized VFD, the controlling of chemical selectivity and reactivity was investigated. Accordingly, the parameters that were effective for controlling of reaction such as rotational speed, tilt angle, flow rate of injection, temperature and concentration of reactants were investigated. In confined mode the optimum condition for the reaction of cyclopentadiene dimerization was achieved in $\theta=45^{\circ}$ and $90^{\circ}$ with $7000 \mathrm{rpm}$ speed and for 1 hour. Therefore, the only changeable parameter for controlling of optimum condition was tilt angle. But in continuous mode concurrently two parameters were changed and the optimum condition was achieved. In first experiment, rotation speed and tilt angle were changed and the results were followed. The optimum condition was in $\theta=90^{\circ}$ and $9000 \mathrm{rpm}$ with $0.1 \mathrm{~mL} / \mathrm{min}$ flow rate. In other experiment two other parameters; flow rate and tilt angle were changed and the results were observed. The optimum condition was achieved in $\theta=45^{\circ}$ and $0.1 \mathrm{~mL} /$ min flow rate with $7000 \mathrm{rpm}$. So related to wanted condition, one of these two modes would be selected. Some other narrative researches that have been performed with the help of VFD are involved bacteria and algal cells with graphene and magnetic polymer [78-80], protein folding [81], exfoliating single layered graphene and hexagonal Boron Nitride (h-BN) sheets from the bulk material [82], sol-gel synthesis of silica xero gel at room temperature and the incorporation of curcumin, [83] controlling the pore size and wall thickness of mesoporous 
Citation: Kamrani H, Nosrati A (2018) Fabrication of Nanofiber Filtration Membranes Using Polyethylene Terephthalate (PET): A Review. J Membr Sci Technol 8: 183. doi:10.4172/2155-9589.1000183

a.

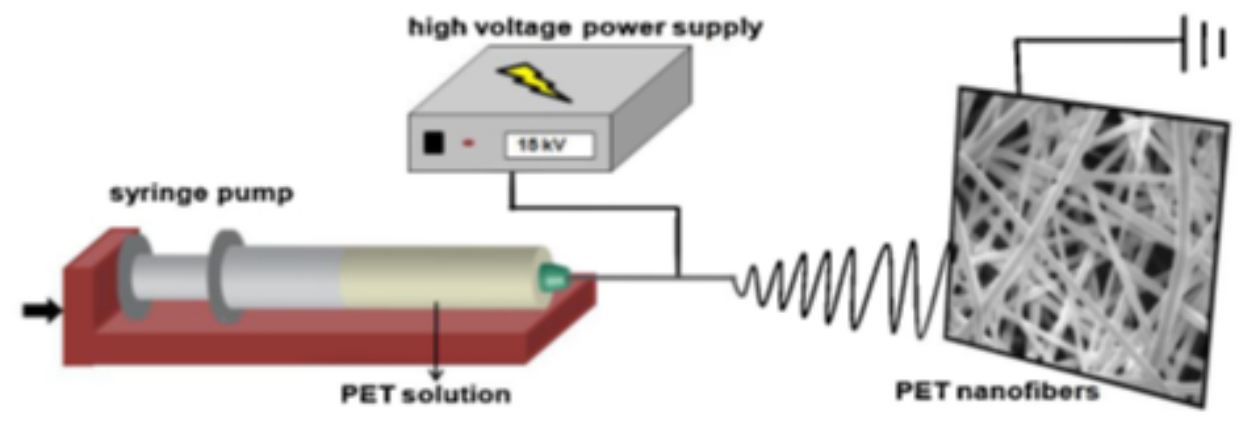

b.
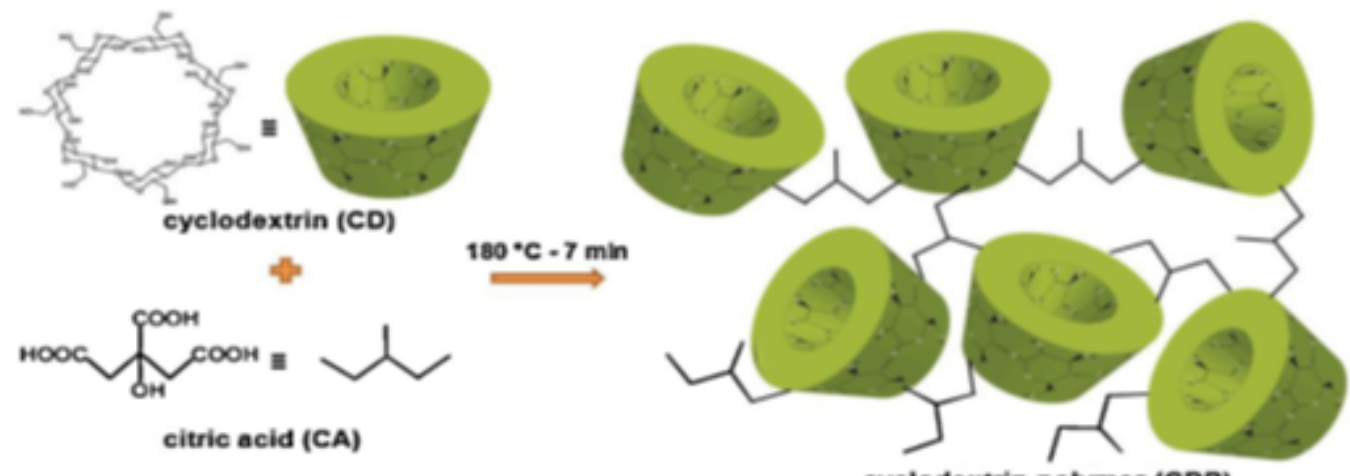

cyclodextrin polymer (CDP)

c.

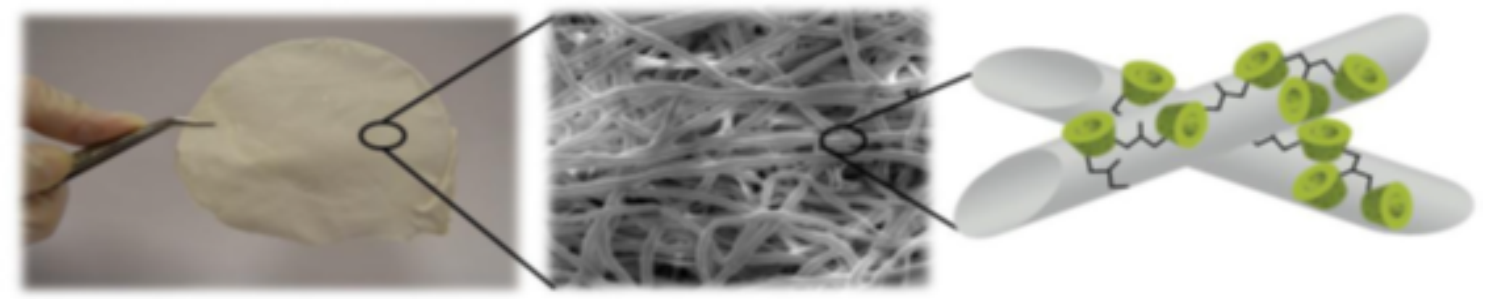

Figure 8: Schematic representations of (a) electrospinning of PET nanofibers, (b) the mechanism of CDP formation and (c) a photograph of PET/CDP nanofibrous mat and its SEM image with a schematic figure of PET/CDP nanofibers [67].

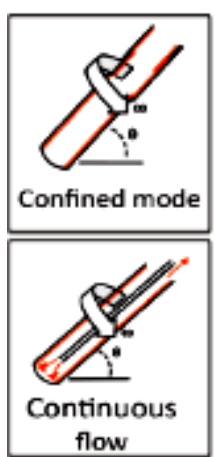

Figure 9: Scheme of continuous flow and confine mode of VFD [73,74].

silica [84,85], fabricating toroidal arrays of SWCNTs, [86] laterally 'slicing' CNTs, [87] accelerating enzymatic reaction, [88] probing the structure of self-organized systems [89,90], biodiesel catalysis [91] and many others. According to the extra capabilities of VFD as a various reaction media compared with Spinning Disc Processors (SDPs) or Rotating Tube Processors (RTPs), VFD will be more advantageous in reaction accomplishment [92]. It seems that it is also a good idea to apply VFD for better making of polymeric solution. For example, we can use PET solution with VFD continuous flow mode and finally the complete homogenous PET solution is charged to an electric force with enough voltage (solution electrospining) to produce better uniform and higher quality nanofiber. Even for specific application we can modify PET solution in VFD with the conjunction of specific chemical or biochemical groups to prepare PET solution and result thin film. Finally with optimization of VFD condition, the best quality concurrently high quantity of nanofiber membrane for water filtration would be achieved.

\section{Conclusion}

The first aim of this mini review was PET and also modified PET membrane fabrication with different methods for water treatment application. The second intention was probable application of VFD as a new device for synthesis of PET membrane as a first idea. The new VFD application idea can optimize the production of a commercial membrane with more probable homogenous and higher quality of nanofibers. Further, we can also apply VFD for recycled PET (rPET) solution production to fabricate low cost high quality membrane .Lower energy consumption and faster reaction with smaller effective volume of reactants during membrane fabrication are other positive results of VFD usage too. At the end the final purpose of recycled bottle grade 
Citation: Kamrani H, Nosrati A (2018) Fabrication of Nanofiber Filtration Membranes Using Polyethylene Terephthalate (PET): A Review. J Membr Sci Technol 8: 183. doi:10.4172/2155-9589.1000183

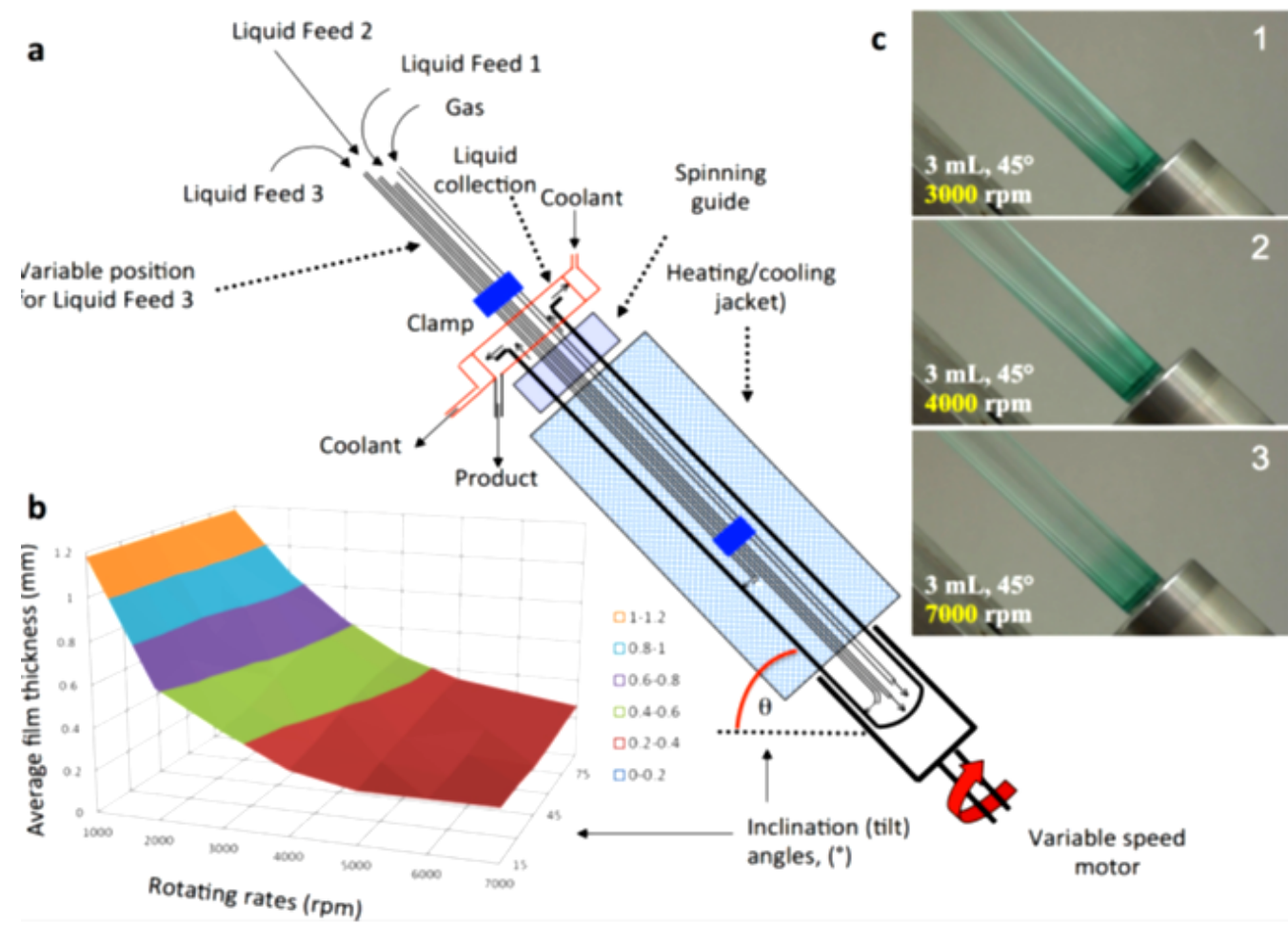

Figure 10: Vortex Fluidic Device (VFD). (a) Cross section showing components of the device; (b) Average film thickness (mm) versus tilt angle ( $\theta$ ); and rotating rates (c) Photographs showing the film of liquid developed for different speeds, for $3 \mathrm{~mL}$ of an aqueous solution, for $\theta=45^{\circ}[77]$.

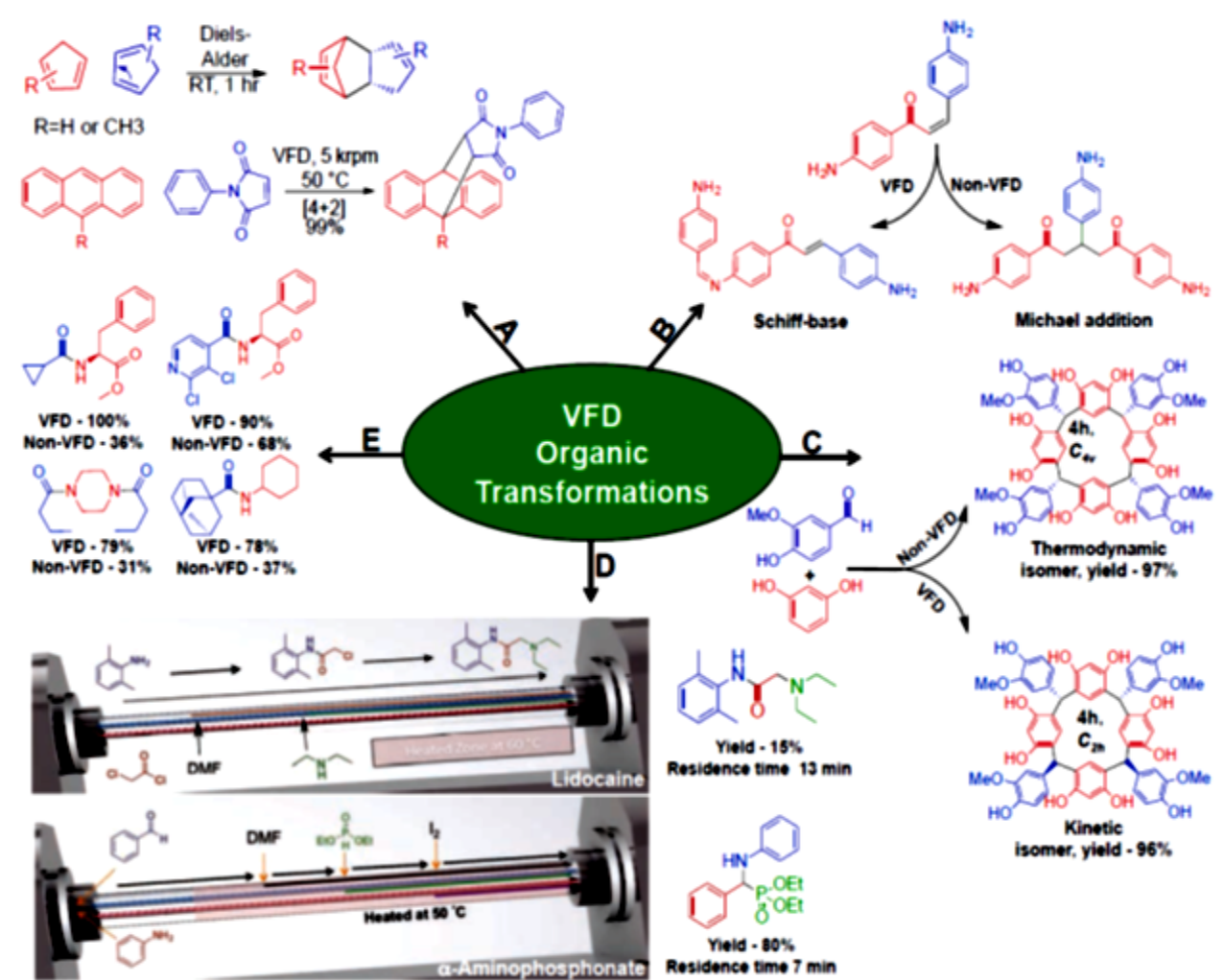

Figure 11: Different reactions with and without VDF application with different followed products [78]. 
PET usage for fabrication of PET membrane would help environment conservation effectively.

\section{Conflict of interest}

None.

\section{References}

1. UN-Water: United Nations Educational, Scientific and Cultural Organization. Water, a shared responsibility: The United Nations World Water Development Report 2. World Water Assessment Programme, 2006.

2. Strathmann $H$ (2001) Membrane separation processes: current relevance and future opportunities. AlChE Journal 47: 1077-1087.

3. Mulder M (1994) The use of membrane processes in environmental problems. An introduction. In Membrane Processes in Separation and Purification. In: Crespo JG, Oddeker WB (eds.), pp. 229-262, Springer.

4. Shen YX (2014) Biomimetic membranes: a review. J Membr Sci 454: 359-381.

5. Vullev VI (2011) From biomimesis to bioinspiration: what's the benefit for solar energy conversion applications. J Phys Chem Lett 2: 503-508.

6. Tang CY (2013) Desalination by biomimetic aquaporin membranes: review of status and prospects, Desalination 308: 34-40

7. Koundouri P, Karousakis K (2012) Water Management in Arid and Semi-Arid regions: Interdisciplinary Perspective, MPRA Paper No.3823.

8. Van der Bruggen B, Vandecasteele C (2002) Distillation vs. membrane filtration: overview of process evolutions in seawater desalination. Desalination 143: 207-218.

9. Wei GL, Yang ZF, Cui BS, Bing Li, Chen H, et al. (2009) Impact of Dam Construction on Water Quality and Water Self-Purification Capacity of the Lancang River, China. Water Resour Manage 23: 1763-1780.

10. Savage N, Diallo MS (2005) Nanomaterials and water purification: opportunities and challenges. Journal of Nanoparticle Research 7: 331-342.

11. Bottero JY, Rose J, Wiesner MR (2006) Nanotechnologies: tools for sustainability in a new wave of water treatment processes. Integrated Environmental Assessment and Management 2: 391-395

12. Qu X, Alvarez PJJ, Li Q (2013) Applications of nanotechnology in water and wastewater treatment. Water Research 47: 3931-3946.

13. Gautam P, Madathil D, Nair ANB (2013) Nanotechnology in waste water treatment: a review. International Journal of ChemTech Research 5: 23032308.

14. Theron J, Walker JA, Cloete TE (2008) Nanotechnology and water treatment: applications and emerging opportunities. Critical Reviews in Microbiology 34 43-69.

15. Amin MT, Alazba AA, Manzoor U (2014) A Review of Removal of Pollutants from Water/Wastewater Using Different Types of Nanomaterials. Hindawi Publishing Corporation Advances in Materials Science and Engineering 1: 1-24

16. Vieno N, Tuhkanen T, Kronberg $L$ (2006) Removal of pharmaceuticals in drinking water treatment: Effect of chemical coagulation. Environmental Technology 27: 183-192.

17. Tansel B (2008) New Technologies for Water and Wastewater Treatment: A Survey of, Recent Patents on Chemical Engineering 1: 17-26.

18. Zabel TF, Melbourne JD (1980) Flotation in Developments in Water Treatment Lewis WM Applied Science Publishers Ltd, London, Vol. 1.

19. Zhang W, DiGiano FA (2002) Comparison of bacterial regrowth in distribution systems using free chlorine and chloramine: A statistical study of causative factors. Water Research 36: 1469-1482.

20. Ozaki H (2004) Rejection of micro-pollutants by membrane filtration. In Proceedings of the Regional Symposium on Membrane Science and Technology, Johor, Malaysia.

21. Wang LK, Vaccari DA, Li Y, Shammas NK, Chemical Precipitation, Physicochemical Treatment Processes, pp. 141-197, Vol. 3.

22. Application of ion exchange process for the treatment of radioactive waste and management of spent ion exchanges, International Atomic Energy Agency, Viena, 2002. Technical reports series No. 408.

23. Kokabian B, Gude VG (2013) Photosynthetic microbial desalination cells (PMDCs) for clean energy, water and biomass production. Environ Sci Process Impact 15: 2178-2185

24. Li Q, Mahendra S, Lyon DY, et al. (2008) Antimicrobial nanomaterials for water disinfection and microbial control: potential applications and implications. Wate Research 42: 4591-4602.

25. Taheri R, Razmjou A, Szekely G, Hou J, Ghezelbash GR (2016) Biodesalination on harnessing the potential of nature's desalination processes. Bioinspir Biomim 11: 1748-3190

26. Zhu Y, Ran T, Li Y, Guo J, Li W (2006) Dependence of the cytotoxicity of multiwalled carbon nanotubes on the culture medium. Nanotechnology 17: 46684674

27. Deng S, Upadhyayula VKK, Smith GB, Mitchell MC (2008) Adsorption equilibrium and kinetics of microorganisms on single-wall carbon nanotubes. IEEE Sensors Journal 8: 954-962.

28. Quinlivan PA, Li L, Knappe DRU (2005)Effects of activated carbon characteristics on the simultaneous adsorption of aqueous organic micropollutants and natural organic matter. Water Research 39: 1663-1673.

29. de Albuquerque Jr. EC, M'endez MOA, dos Reis Coutinho A, Franco TT (2008) Removal of cyanobacteria toxins from drinking water by adsorption on activated carbon fibers. Materials Research 11: 371-380.

30. Prof. Dr. Eckhard Worch Dresden University of Technology Institute of Water Chemistry, adsorption technology in water treatment, Fundamentals, Processes, and Modeling, ISBN 978-3-11-024022-1, e-ISBN 978-3-11-024023-8.

31. Habibi MH, Kamrani R (2012) Photocatalytic mineralization of methylene blue from water by a heterogeneous copper-titaniananocomposite film. Desalination and Water Treatment 46: 278-284.

32. Baker RW (2004) Membrane Technology and Applications, John Wiley \& Sons, Ltd, West Sussex, England.

33. Khayet M, Matsumura T (2011) Membrane Distillation: Principles and Applications, Elsevier, Oxford, U.K.

34. Alkhudhiri A, Darwish N, Hilal N (2012) Membrane distillation: a comprehensive review. Desalination 287: 2-18.

35. Chen W, McCarthy TJ (1998) Polymer Science and Engineering Departmen University of Massachusetts, Amherst, Massachusetts 01003, Chemical Surface Modification of Poly(ethylene terephthalate). Macromolecules 31 : 3648-3655.

36. Lee HL, Lim KS, Hahm WG, Kim SH (2013) Properties of recycled and virgin poly(ethylene terephthalate) blend fibers. J Appl Polym Sci 128: 1250-1256.

37. Brennan LB, Isaac DH, Arnold JC (2002) Recycling of acrylonitrile-butadienestyrene and high-impact polystyrene from waste computer equipment. J Appl Polym Sci 86: 572-578

38. Elmaghor F, Zhang L, Fan R, Li H (2004) Recycling of polycarbonate by blending with maleic anhydride grafted ABS. Polymer 45: 6719-6724.

39. Sanchez EMS (2007) Ageing of PC/PBT blend: Mechanical properties and recycling possibility. Polym Test 26: 378-387

40. Zander NE, Sweetser D, Cole DP, Gillan M (2016) Formation of Nanofibers from Pure and Mixed Waste Streams Using Electrospinning. Materials 9: 247.

41. Prince JA, Singh G, Rana D, Matsuura T, Anbharasi V, et al. (2012) Preparation and characterization of highly hydrophobic poly(vinylidene fluoride) clay nanocomposite nanofiber membranes (PVDF-clay NNMs) for desalination using direct contact membrane distillation. J Membr Sci 397-398: 80-86.

42. Lalia BS, Guillen-Burrieza E, Arafat HA, Hashaikeh R (2013) Fabrication and characterization of polyvinylidenefluoride-co-hexafluoropropylene (PVDF-HFP) electrospun membranes for direct contact membrane distillation. J Membr Sci 428: 104-115.

43. Gopal R, Kaur S, Ma Z, Chan C, Ramakrishna S, et al. (2006) Electrospun nanofibrous filtration membrane. J Membr Sci 281: 581-586.

44. Taylor G (1969) Electrically driven jets. Proc R Soc London, Ser A, 313 453-475. 
45. Zander NE, Gillan M, Sweetser D (2016) Recycled PET Nanofibers for Water filtration Applications. Materials 9: 247

46. Rajabinejad H, Khajavi R, Rashidi A, Mansouri N, Yazdanshenas ME (2009) Recycling of Used Bottle Grade Poly Ethyleneterephthalate to Nanofibers by Melt-lectrospinning Method. Int J E nviron Res 3: 663-670.

47. Elaheh E, Fatemeh D, Seyyed AR (2017) Synthesis and characterization of the electrospun fibers prepared from waste polymeric materials. Int J NanoDimens 8: 171-181.

48. Shirazi A, Mahdi M, Kargari A, Ramakrishna S, Doyle J, at al. (2017) Electrospun Membranes for Desalination and Water/Wastewater Treatment: A Comprehensive Review. Journal of Membrane Science and Research 3 209-227.

49. Wang C, Wang L, Zhu X, Wang Y, Xue J (2012) Low-voltage electroosmotic pumps fabricated from track-etched polymer membrane. Lab Chip 12 : 1710-1716.

50. Komaki Y, Tsujimura S (1976) Growth of fine holes in polyethylenenaphthalate film irradiated by fission fragments. J Appl Phys 47: 13550-1358.

51. Kravets LI, Dmitriev SN, Satulu V, Mitu B, Dinescu G (2014) Structure and electrochemical properties of track membranes with a polymer layer obtained by plasma polymerization of acetylene. Journal of Physics: Conference Series 516: 012006

52. Zhang Y, Kong XY, Gao L, Tian Y, Wen L (2015) Fabrication of Nanochannels. Materials 8: 6277-6308.

53. Sartowska BA (2012) Nanopores with controlled profiles in track-etched membranes. Nukleonika 57: 575-579.

54. Zander NE, Gillan M, Sweetser D (2017) Composite Fibers from Recycled Plastics Using Melt Centrifugal Spinning, Materials 10: 1044.

55. Trofimov DA, Shkinev VM, Spivakov BY (2017) Modification of the surface and pores of poly (ethylene terephthalate) track membranes using $\mathrm{N}$-isopropylacrylamide for an improvement of membrane performances. Mendeleev Communications 27: 44-46.

56. Hilal N, Khayet M, Wright CJ (2016) Membrane modification: Technology and applications. CRC press.

57. Tsai PP, Schreuder-GH, Gibson P (2002) Different electrostatic methods for making electret filters. Journal of Electrostatics 54: 333-341.

58. Xue L, Greisler HP (2003) Biomaterials in the development and future of vascular grafts. Journal of vascular surgery $37: 472-480$.

59. Ratcliffe A (2000) Tissue engineering of vascular grafts. Matrix Biology 19: 353-357.

60. Jarrell BE, Williams SK, Stokes G, Hubbard FA, Carabasi RA, et al. (1986) Use of freshly isolated capillary endothelial cells for the immediate establishment of a monolayer on a vascular graft at surgery. Surgery 100: 392-399.

61. Deutsch M, Meinhart J, Fischlein T, Preiss P, Zilla P (1999) Clinical autologous in vitro endothelialization of infrainguinal ePTFE grafts in 100 patients: a 9-year experience. Surgery 126: 847-855.

62. Mendelsohn JD, Barrett CJ, Chan VV, Pal AJ, Mayes AM, et al. (2000) Fabrication of microporous thin films from polyelectrolyte multilayers. Langmuir 16: $5017-5023$

63. Fang J, Wang X, Lin T (2011) Functional applications of electrospun nano fibers, In Nano fibers-production, properties and functional applications. InTech.

64. Arahman N, Fahrina A, Amalia S, Sunarya R, Mulyati S (2017) Effect of PVP on the characteristic of modified membranes made from waste PET bottles for humic acid removal. F1000 Research 6.

65. Kim K, Kim H, Lim JH, Lee SJ (2016) Development of a desalination membrane bioinspired by mangrove roots for spontaneous filtration of sodium ions. ACS nano 10: 11428-11433.

66. Abdel-Hady EE, Abdel-Hamed MO, Gomaa MM (2013) Preparation and Characterization of Commercial Polyethyleneterephthalate Membrane for Fue Cell Applications. J Membra Sci Technol 3: 2.

67. Kayaci F, Aytac Z, Uyar T (2013) Surface modification of electrospun polyester nanofibers with cyclodextrin polymer for the removal of phenanthrene from aqueous solution. Journal of hazardous materials 261: $286-294$.
68. Homaeigohar S, Elbahri M (2014) Nanocomposite electrospun nanofiber membranes for environmental remediation. Materials 7: 1017-1045

69. Ma H, Yoon K, Rong L, Mao Y, Mo Z, et al. (2010) High-flux thin-film nanofibrous composite ultrafiltration membranes containing cellulose barrier layer. J Mater Chem 20: 4692-4704.

70. Li G, Wang J, Hou D, Bai Y, Liu H (2016) Fabrication and performance of PET mesh enhanced cellulose acetate membranes for forward osmosis. Journal of Environmental Sciences 45: 7-17.

71. Veleirinho B, Lopes-da-Silva JA (2009) Application of electrospun poly (ethylene terephthalate) nanofiber mat to apple juice clarification. Process Biochemistry 44: 353-356.

72. Jianguo $Z$ (2015) The modification effect of gamma-ray grafting of TiO2 on PET film. Journal of Experimental Nanoscience 10: 1116-1125.

73. Chen X, Dobson JF, Raston CL (2012) Vortex fluidic exfoliation of graphite and boron nitride. Chem Commun 48: 3703-3705.

74. Britton J, Dalziel SB, Raston CL Continuous flow Fischer esterifications harnessing vibrational-coupled thin film fluidics. RSC Advances 5: 1655-1660.

75. Yasmin L, Chen X, Stubbs KA, Raston CL (2013) Optimising a vortex fluidic device for controlling chemical reactivity and selectivity. Sci Rep 3: 2282.

76. Aoune A, Ramshaw C (1999) Process intensification: heat and mass transfer characteristics of liquid films on rotating discs. International Journal of Heat and Mass Transfer. 42: 2543-2556.

77. Colin LR, Geregory AW. Vortex fluidic chemical transformation, mini review. WILEY-VCH. 201.

78. Yuan TZ, Ormonde CF, Kudlacek ST, Kunche S, Smith JN, et al. (2015) ShearStress-Mediated Refolding of Proteins from Aggregates and Inclusion Bodies. ChemBioChem 16: 393-396.

79. Wahid MH, Eroglu E, Chen X, Smith SM, Raston CL (2013) Functional multilayer graphene-algae hybrid material formed using vortex fluidics. Green Chemistry. 15: 650-655.

80. Wahid MH, Eroglu E, Chen X, Smith SM, Raston CL (2013) Entrapment of Chlorella vulgaris cells within graphene oxide layers. Rsc Advances 3 . 8180-8183.

81. Vimalanathan K, Shrestha RG, Zhang Z, Zou J, Nakayama T, et al. (2017) Surfactant-free Fabrication of Fullerene C60 Nano tubules Under Shear. Angewandte Chemie International Edition. 56: 8398-8401.

82. Eroglu E, D'Alonzo NJ, Smith SM, Raston CL (2013) Vortex fluidic entrapment of functional microalgal cells in a magnetic polymer matrix. Nanoscale. 5: 2627-2631.

83. Chen X, Dobson JF, Raston CL (2012) Vortex fluidic exfoliation of graphite and boron nitride. Chemical Communications 48: 3703-3705

84. Tong CL, Stroeher UH, Brown MH, Raston CL (2015) Continuous flow vortex fluidic synthesis of silica xerogel as a delivery vehicle for curcumin. RSC Advances 5: 7953-7958.

85. Tong CL, Boulos RA, Yu C, lyer KS, Raston CL (2013) Continuous flow tuning of ordered mesoporous silica under ambient conditions. RSC Advances 3: 18767-18770.

86. Tong CL, Eroglu E, Duan X, Lamb RN, Jarrett K, et al. (2015) Nitrate uptake using mesoporous silica embedded with zero-valent palladium nanoparticles. RSC Advances 5: 20557-20561.

87. Vimalanathan K, Chen X, Raston CL (2014) Shear induced fabrication of intertwined single walled carbon nanotube rings. Chemical Communications 50: $11295-11298$

88. Vimalanathan K, Gascooke JR, Suarez-Martinez I, Marks NA, Kumari H, et al (2016). Fluid dynamic lateral slicing of high tensile strength carbon nanotubes. Sc Rep 6: 22865.

89. Britton J, Meneghini LM, Raston CL, Weiss GA (2016) Accelerating enzymatic catalysis using vortex fluidics. Angewandte Chemie International Edition. 55 11387-11391.

90. Mo J, Eggers PK, Chen X, Ahamed MRH, Becker T, et al. (2015) Shear induced carboplatin binding within the cavity of a phospholipid mimic for increased anticancer efficacy. Scientific reports. 5: 10414. 
Citation: Kamrani H, Nosrati A (2018) Fabrication of Nanofiber Filtration Membranes Using Polyethylene Terephthalate (PET): A Review. J Membr Sci Technol 8: 183. doi:10.4172/2155-9589.1000183

Page 11 of 11

91. Iyer KS, Raston CL (2007) Fabrication of laterally 'sliced'metal plated carbon nanotubes under aqueous continuous flow conditions. Journal of Materials Chemistry 17: 4872-4875.
92. Britton J, Chalker JM, Raston CL (2015) Rapid Vortex Fluidics: Continuous Flow Synthesis of Amides and Local Anesthetic Lidocaine. Chemistry-A European Journal 21: 10660-10665. 